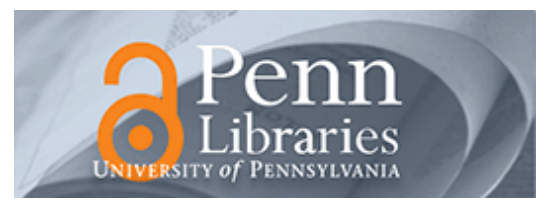

University of Pennsylvania

ScholarlyCommons

Marketing Papers

Wharton Faculty Research

$3-2010$

\title{
Positive Effects of Negative Publicity: When Negative Reviews Increase Sales
}

Jonah A. Berger

University of Pennsylvania

Alan T. Sorensen

Scott J. Rasmussen

Follow this and additional works at: https://repository.upenn.edu/marketing_papers

Part of the Marketing Commons

\section{Recommended Citation}

Berger, J. A., Sorensen, A. T., \& Rasmussen, S. J. (2010). Positive Effects of Negative Publicity: When Negative Reviews Increase Sales. Marketing Science, 29 (5), 815-827. http://dx.doi.org/10.1287/ mksc.1090.0557

This paper is posted at ScholarlyCommons. https://repository.upenn.edu/marketing_papers/198

For more information, please contact repository@pobox.upenn.edu. 


\title{
Positive Effects of Negative Publicity: When Negative Reviews Increase Sales
}

\author{
Abstract \\ Can negative information about a product increase sales, and if so, when? Although popular wisdom \\ suggests that "any publicity is good publicity," prior research has demonstrated only downsides to \\ negative press. Negative reviews or word of mouth, for example, have been found to hurt product \\ evaluation and sales. Using a combination of econometric analysis and experimental methods, we unify \\ these perspectives to delineate contexts under which negative publicity about a product will have positive \\ versus negative effects. Specifically, we argue that negative publicity can increase purchase likelihood \\ and sales by increasing product awareness. Consequently, negative publicity should have differential \\ effects on established versus unknown products. Three studies support this perspective. Whereas a \\ negative review in the New York Times hurt sales of books by well-known authors, for example, it \\ increased sales of books that had lower prior awareness. The studies further underscore the importance \\ of a gap between publicity and purchase occasion and the mediating role of increased awareness in \\ these effects. \\ Keywords \\ negative publicity, awareness, word of mouth, product success \\ Disciplines \\ Business | Marketing
}


Positive Effects of Negative Publicity: When Negative Reviews Increase Sales

JONAH BERGER

ALAN T. SORENSEN

SCOTT J. RASMUSSEN*

forthcoming, Marketing Science

* Jonah Berger is Assistant Professor of Marketing, The Wharton School, University of Pennsylvania (email: jberger@wharton.upenn.edu). Alan T. Sorensen is Associate Professor of Strategic Management, Stanford Graduate School of Business (email: asorensen@stanford.edu). Scott J. Rasmussen is an alumnus of Stanford University (email: scott.rasmussen@stanfordalumni.org). The authors are grateful to Eric Bradlow, Chip Heath, Wes Hutchinson, John Lynch, Dina Mayzlin, Matthew Salganik, Christophe Van den Bulte, Christian Wheeler, and participants at Stanford's Café Verona Session for helpful feedback on various versions of the manuscript, to Lisa Falzone for research assistance, to Young Lee for helped implement Studies 2 and 3, and to Annalisa Mastri for invaluable data and editing assistance. 


\begin{abstract}
Can negative information about a product increase sales, and if so, when? Although popular wisdom suggests that "any publicity is good publicity," prior research has demonstrated only downsides to negative press. Negative reviews or word-of-mouth, for example, have been found to hurt product evaluation and sales. Using a combination of econometric analysis and experimental methods, the authors unify these perspectives to delineate contexts under which negative publicity about a product will have positive versus negative effects. Specifically, they argue that negative publicity can increase purchase likelihood and sales by increasing product awareness. Consequently, negative publicity should have differential effects on established versus unknown products. Three studies support this perspective. While a negative review in the New York Times hurt sales of books by well-known authors, for example, it increased sales of books that had lower prior awareness. The studies further underscore the importance of a gap between publicity and purchase occasion and the mediating role of increased awareness in these effects.
\end{abstract}

KEYWORDS: Negative Publicity, Awareness, Word-Of-Mouth, Product Success 
Negative publicity often hurts. When a rumor circulated that McDonald's used worm meat in its hamburgers, sales decreased by over 25\% (Greene 1978). Coverage of musician Michael Jackson's bizarre behavior and brushes with the law destroyed his career. Viacom Inc. chairman Sumner Redstone estimated that negative publicity cost Mission Impossible 3 over \$100 million in ticket sales (Burrough 2006) and film pundits have suggested that it is "almost impossible to recover from bad buzz" (James 2006).

Academic research corroborates this sentiment, and casts further doubt on the old adage that "any publicity is good publicity." Negative publicity about a product has been shown to hurt everything from product and brand evaluation (Tybout, Calder, and Sternthal 1981; Wyatt and Badger 1984) to firm NPV and sales (Goldenberg, Libai, Moldovan, and Muller 2007; Reinstein and Snyder 2005). Negative movie reviews, for example, decrease box office receipts (Basuroy, Chatterjee, and Ravid 2003).

A number of intriguing examples, however, seem to contradict these findings. A wine described "as redolent of stinky socks," for example, saw its sales increase by 5\% after it was reviewed by a prominent wine website (O'Connell 2006). Similarly, while the movie Borat made relentless fun of the country of Kazakhstan, Hotels.com reported a "300 percent increase in requests for information about the country" after the film was released (Yabroff 2006, p. 8). Though these may just be idiosyncratic examples, they suggest that negative publicity may not always be a bad thing. Can negative publicity actually have a positive effect? And if so, when?

This manuscript examines negative publicity. Specifically, we build on both behavioral and quantitative research to delineate contexts under which negative publicity about a product will have positive versus negative effects on product choice and sales. In 
the spirit of connecting consumer psychology and marketing science (Winer 1999; Wittink 2004), we then test our predictions using both experimental methods and an econometric analysis of book reviews and sales. Finally, we discuss the implications of these findings for advertising and the success of cultural products more broadly.

\section{NEGATIVE EFFCTS OF NEGATIVE INFORMATION}

Research from a variety of perspectives has found that negative information hurts. Behavioral work has examined how negative information affects product impressions. Not surprisingly, negative reviews, messages, or rumors hurt product evaluations and reduce purchase likelihood and sales (Huang and Chen 2006; Wyatt and Badger 1984; Tybout, et al. 1981). Quantitative work has investigated how reviews influence sales. Focusing on critics, a thumbs-down from Siskel and Ebert (Reinstein and Snyder 2005), or negative movie reviews more broadly (Basuroy, et al. 2003) decrease box office revenue. Similar effects have been shown for consumer reviews: one-star reviews hurt book sales on Amazon.com, for example (Chevalier and Mayzlin 2006; also see Clemons, Gao and Hitt 2006; Dellarocas, Zhang, and Awad 2008; Moe 2009). Thus while idioms may suggest that any publicity is good publicity, all existing studies of negative publicity have found its effects to be negative. Though such negative effects may be lessened for high commitment consumers (Ahluwalia, Burnkrant, and Unnava 2000) we are unaware of any research that has found upsides of negative press.

\section{ROUTES THROUGH WHICH PUBLICITY INFLUENCES BEHAVIOR}

In contrast, we suggest that negative publicity can sometimes increase purchase 
likelihood and sales. One way publicity can influence product success is through influencing product evaluations. This can be thought of as the persuasive impact of publicity (Liu 2006; Van den Bulte and Lilien 2001). If a critic gives a book a negative review, this may lead consumers to think the book is bad, and reduce their likelihood of buying it. But because negative information should generally decrease product evaluations, or at best leave them unchanged, attitude change alone cannot explain why negative publicity would ever increase product choice or sales.

We argue that negative publicity may have positive effects, however, by increasing product awareness or accessibility. Consideration appears to explain much of choice (Hauser 1978). Consumers have finite attention, and the sheer multitude of cultural offerings means that most consumers will not be aware of every book, movie, or album that is released. Similarly, people may know about a product, but information varies it its accessibility (Higgins and King 1981; Wyer and Srull 1981) and is less likely to affect behavior when it is not top of mind. Consumers may know that Mission Impossible 3 recently came out on DVD, for example, but if it doesn't come to mind when they are at the video store, they are not going to rent it. Advertising, or related cues in the environment, can thus increase choice and sales by informing consumers of a product's existence (Stigler 1961) or increasing product accessibility (Berger and Fitzsimons 2008; Nedungadi 1990), respectively (see Lynch and Srull 1982). Similarly, regardless of valence, publicity (and potentially word-of-mouth) may have positive effects if it makes consumers more aware or encourages the product to be top-of-mind.

This distinction between evaluation and awareness or accessibility is analogous to prior work on different effects of advertising (Mitra and Lynch 1995). Advertising can 
affect preferences for various options given they are considered, but it can also affect choice by changing which options consumers consider, interpedently of their preferences for those options.

\section{THE CURRENT RESEARCH}

Building on this analysis, we suggest that whether negative publicity has positive or negative effects will depend on existing product awareness and accessibility. When awareness is high, negative publicity should hurt sales. If most consumers already know that Mission Impossible 3 is about to come out on DVD, or there is a lot of buzz about a new Stephen King book, the potential increase in awareness or accessibility generated by negative publicity should be negligible. Negative publicity should lower product evaluation, however, and consequently, decrease consumer choice.

Along these lines, prior quantitative work may have found negative effects of negative publicity because they examined products which already had considerable awareness. The average film in Basuroy et al.'s (2003) analysis, for example, grossed over $\$ 5$ million in the first week (in the early 1990s) and was reviewed by more than 30 critics. These numbers place the set of films at the more popular end of films released over that period (www.boxofficeguru.com). More generally, most prior work has studied well-advertised cultural products that many consumers likely knew about already.

In contrast, through increasing awareness, negative publicity may increase sales when product awareness or accessibility is low. If few people know about a book released by a new author, any publicity, regardless of valence, should increase awareness. While it focuses more on accessibility than awareness, this suggestion is analogous to 
work by Nedungadi (1990) showing that cues which activate related brands only have effects in situations where consideration is unlikely without a reminder. In addition, negative publicity may be even more likely to boost sales if awareness and publicity valence become dissociated in memory. Similar to the sleeper effect (Hannah and Sternthal 1984), where source information tends to become dissociated from the message over time, people may have a feeling of awareness, or remember they heard something about the product, but the valence may be forgotten (also see Skurnik et al. 2005). Work on advertising, for example, theorizes that even negative ads might boost purchase likelihood after delay because it increases brand awareness (Moore and Hutchinson 1983; 1985).

This dissociation should be particularly likely when product awareness is low. First, product familiarity increases involvement and motivation (Petty and Cacioppo 1979), while decreasing the cognitive effort necessary to process information (Alba and Hutchinson 1987). Consequently, lower involvement and higher required effort for unfamiliar products should decrease processing and encoding of publicity related information. Second, while familiar products have strong memory networks, unknown products have little existing cognitive structures making it harder to incorporate and recall new information (Alba and Hutchinson 1987; Anderson 1995). Both these factors should make publicity valence for unknown products more likely to fade over time. The increased awareness, however, may lead even negative publicity to increase purchase.

Three studies test these hypotheses using a combination of experimental methods and econometric analysis. Study 1 examines the performance of books reviewed in the New York Times to investigate the effect of publicity valence and product awareness on 
actual book sales. Study 2 examines the role that time between publicity and choice plays in positive effects of negative publicity. Finally, Study 3 directly investigates the mediating role of increased awareness in these effects.

\section{STUDY 1: NEW YORK TIMES BOOK REVIEWS}

Study 1 uses weekly sales data to estimate the impact of New York Times book reviews on the sales of over 200 hardcover fiction titles. The reviews themselves are systematically classified as positive or negative in order to distinguish the effects of good and bad publicity. Inferring the impact of book reviews by comparing reviewed books to non-reviewed books is obviously problematic, since the New York Times' decision to review a book may depend on its potential popularity. In order to avoid potential endogeneity bias, our analysis focuses solely on reviewed books, using time series variation in sales (for a given book) to identify the effect of published reviews. Essentially, we measure the spike in sales in the week immediately following the book review, and ask whether the spike is different for positive and negative reviews.

We also examine whether the effect of being reviewed varies based on product awareness prior to the review. Hundreds of books are released each week, so consumers cannot possibly know about all of them. Consequently, books by relatively new authors (e.g., Dirk Wittenborn) have much to gain from the awareness that reviews provide. In contrast, books by more well-established authors (e.g., John Grisham or Stephen King) should already be somewhat familiar and thus publicity's ability to boost awareness or accessibility should be reduced (see Nedungadi 1990). We predict that while positive publicity should increase sales for all types of authors, the effect of negative publicity 
will depend on existing product awareness. Negative publicity should hurt book sales of established authors, but boost sales of authors that are relatively unknown.

\section{Method}

Our dataset consists of weekly national sales for 244 hardcover fiction titles that were released from 2001 to 2003 and reviewed by the New York Times. For consistency's sake, paragraph-length reviews and articles mentioning multiple books are omitted, so only full-length reviews are included in the sample. The sales data were provided by Nielsen BookScan, a market research firm that tracks book sales using scanner data from an almost-comprehensive panel of retail booksellers. BookScan collects data through cooperative arrangements with virtually all the major bookstore chains, most major discount stores (e.g., Costco), and most of the major online retailers (e.g., Amazon.com). They claim to track at least 80 percent of total retail sales. Additional information about individual titles (such as publication date, subject, and author information) was obtained from a variety of sources, including Amazon.com and Overbooked.org.

Unlike movie critics, book reviewers do not use stars or thumbs-up/thumbs-down systems to summarize their opinions, so we had to do it for them. In order to avoid subjective biases, we attempted to do this in a systematic way. Typical reviews consist primarily of non-opinionated prose describing the book's characters and plot, so we flagged the sentences likely to be opinionated by using a textual search algorithm (looking for keywords such as the author's name or the word "writing"), ${ }^{1}$ randomized

\footnotetext{
${ }^{1}$ Details of the Perl script used to find opinionated sentences are available on request. The algorithm prioritized Type II rather than Type I error minimization in order to limit the number of opinionated sentences excluded from the analysis: 42.3 percent of flagged sentences were opinionated, whereas among a sample of 200 unflagged sentences only 18 (9 percent) were opinionated.
} 
them, and then scored them individually as positive, negative, or neutral. Each potentially opinionated sentence is therefore evaluated on its own merit. The relative opinion score for each book was then calculated as the ratio of positive sentences to opinionated sentences; for example, a book with $P$ positive sentences and $N$ negative sentences received a score of $P /(P+N)$. In the econometric analysis, reviews are categorized as negative when the ratio is below $50 \%$ and positive otherwise. The resulting estimates are similar if publicity valence is kept as a continuous measure, if publicity valence is calculated other ways, or if other negative publicity cut-offs (e.g., below 33\% positive statements) are used. ${ }^{2}$ Summary statistics are reported in Table 1.

The primary motivation for this approach, which essentially involves removing opinionated sentences from the larger context of the review, was to avoid confounding subjective opinions about a book's content with objective evaluations of the reviewer's critique. For example, a reader enthused about the history of the American West may believe that a review of a Western novel is positive, even though the reviewer criticizes the novel as dull or otherwise poorly written. We expect our measure to differ somewhat from (but still be positively correlated with) scores based on an individual's subjective reading of the reviews; our intent is to approximate the average subjective reading in the population (e.g., averaging over readers who do and don't like Westerns). ${ }^{3}$

\footnotetext{
${ }^{2}$ A possible drawback to our method is that it doesn't give extra weight to extreme expressions of opinion: e.g., a review with five mildly positive sentences and one sentence saying "this is the worst novel I've ever had the misfortune to read" will still be characterized as a positive review. However, given that reviewers who write for the New York Times are given to relatively nuanced prose, and blunt expressions of extreme opinion are rare, this possibility seems like less of a concern.

${ }^{3}$ Indeed, when a research assistant read 100 reviews and scored them on a five-point negative-positive scale, her scores were significantly correlated with our measure $(\mathrm{r}=.44, p<.02)$. Again, since individual readers may perceive a review differently, it is difficult to infer too much from this relationship, but the fact that it is significant supports the notion that our measure adequately captured the valence of the review. Further, any imprecision in our classification should introduce noise and make it harder to find any effects.
} 
Our analysis focuses on reviewed books, identifying the impact of reviews from the time series variation in sales for a given book. We restrict our attention to the nineweek window surrounding each book's review week (the review week plus up to four weeks pre- and post-review). As indicated in Table 1, most books are reviewed shortly after their release. In some cases, reviews are published within one week of a book's release; we were forced to omit such books from our sample, since we would have no pre-review sales trajectory to use as a benchmark for measuring the impact of the review.

Suppose that sales of book $i$ in week $t$ are given by

$$
s_{i, t}=s_{i, t-1} \cdot \exp \left\{x_{i, t}^{\prime} \beta\right\} \cdot \varepsilon_{i, t}
$$

so that

$$
\ln \left(\frac{s_{i, t}}{s_{i, t-1}}\right)=x_{i, t}^{\prime} \beta+u_{i, t}
$$

We take equation 2 as the model to be estimated. ${ }^{4}$ The dependent variable is the log of the sales ratio: today's sales as a fraction of yesterday's sales. Note that one advantage of this specification is that it puts all books on the same scale, even though the sales levels vary dramatically across books in the sample. Another motivation for this specification relates to its predictive power: since measuring the impact of book reviews requires knowing what sales would have looked like in the absence of a review, we want a model that does a good job predicting the path of sales. Allowing sales to depend on lagged sales generates predicted sales paths that are smoother and more accurate than what

\footnotetext{
${ }^{4}$ We used this particular equation because prior work has shown that the sales of cultural products tend to peak in the first few weeks and then exponentially decline (Hendricks and Sorensen 2007). Indeed, in our own data, over $85 \%$ of books had downward trending sales over the first three months.
} 
would be obtained from a model containing only contemporaneous explanatory variables. Also, note that since we use time series variation to identify the impact of reviews, in order for endogeneity bias to be a problem it would have to be the case that reviews are systematically timed to correspond with large unobserved demand shocks - which is a relatively implausible scenario.

Our vector of covariates, $X_{i, t}$, contains variables related to book reviews (e.g., an indicator for whether a review of book $i$ appeared in week $t$ ) as well as week dummies (one for each of the 110 weeks represented in the sample, to control for time trends and seasonal variation in book demand), weeks since the book was released, and indicators for whether the book was announced as a television book club pick. The errors, $u_{i, t}$, are assumed to be independent across books but potentially heteroskedastic across books and potentially dependent over time for a given book. ${ }^{5}$

We investigate whether the impact of positive and negative reviews vary based on existing awareness. Using our measure of reviews' opinions, we categorize reviews as positive or negative and estimate the impact of reviews among three categories of authors: those that have published one or fewer books prior to the book in question, those that have published between two and nine, and those that have published ten or more. ${ }^{6}$ We then estimate the regression with separate review dummies for each of the six categories implied by 2 (Review Valence) x 3 (Author Category).

\footnotetext{
${ }^{5}$ In the reported results, we simply present standard errors that are robust to the potential heteroskedasticity and within-group dependence. Testing directly for serial correlation in the errors is not a trivial exercise in this context; however, when the models are estimated assuming that $u$ follows an AR(1) process, the results are largely unaffected.

${ }^{6}$ Results are similar when other similar groupings are used.
} 


\section{Results}

As predicted, whether being reviewed increased or decreased sales depended on both review valence and existing product awareness (Table 2). Regardless of whether the book was written by a new or established author, being positively reviewed significantly increased sales; a positive review generated between a $32 \%$ and $52 \%$ percent increase in demand (no significant difference between coefficients, $\mathrm{z}=1.0, p>.30$ ) In contrast, estimates indicate that the effect of negative publicity depended on existing author awareness $(\mathrm{z}=2.30, p<.05)$. For books by established authors, a negative review led to a $15 \%$ decrease in sales (this estimate is slightly imprecise due to the relatively small sample size). For books by relatively unknown (new) authors, however, negative publicity has the opposite effect, increasing sales by $45 \%$.

Comparing the coefficients for positive and negative publicity for different categories of authors provide additional insight. While positive and negative publicity had different effects on the sales of books by established authors $(z=2.75, p<.01)$, they had similar effects on books by new authors $(z=.11, p>.90)$. Treating review valence as a continuous variable underscores this pattern of results. Again, the results indicate review valence had different effects on sales of books by new versus established authors $(\mathrm{z}=1.98, p<.05)$. While review valence had a significant effect on the sales of books by established authors $(\mathrm{B}=0.45, \mathrm{~S} . \mathrm{E} .=0.19, t=2.38, p<.02)$ it had little effect on the sales of books by new authors $(\mathrm{B}=-0.07$, S.E. $=0.18, p>.70)$. For books which should have relatively lower awareness, both positive and negative publicity increased sales.

Finally, geographic variation in the effects bolsters our suggestion that reviews had a causal effect. Though the New York Times is read widely throughout the nation, its 
readership is still somewhat concentrated in New York City (New York Times Company, 2006). Given this geographical dispersion, if reviews are truly having a causal effect on sales, one would expect the impact to be larger in New York City. We were able to obtain designated market area (DMA) specific sales data for a small sub-sample of 33 books that allowed us to test this possibility. Nielsen defines DMAs for the purpose of studying geographic variation in sales and the DMAs generally encompass entire metropolitan areas: e.g., the New York, NY DMA includes Brooklyn and Queens and Manhattan, etc. As expected, the estimated effect of book reviews is much stronger in New York City $(B=0.81$, S.E. $=0.14)$ than the other DMAs $(B=0.44$, S.E. $=0.09$ : $F(1,32)=4.81, p<.05)$. This suggests that reviews have a causal effect on sales.

\section{Discussion}

Can negative publicity ever increase sales? An analysis of New York Times reviews and book sales suggests it can. Relative to not being covered, being reviewed in the Times increased a book's sales, even in some instances where a reviewer panned the book. The book Fierce People, for example, was written by an new author and received an unambiguously negative review (e.g., "the characters do not have personalities so much as particular niches in the stratosphere" and "He gets by on attitude, not such a great strategy if the reader can't figure out what that attitude is") yet sales more than quadrupled after the review.

More importantly, the results delineate conditions under which negative publicity will have positive versus negative effects. While positive reviews always increased sales, the effect of negative reviews depended on whether the authors were new or well- 
established. As predicted, a negative review hurt sales of books by well-established authors, but helped sales of books by relatively unknown authors. This is consistent with our suggestion that the effects of negative publicity depend on existing product awareness.

In addition, the pattern of results also supports our suggestion regarding the role that product awareness plays in the stickiness of publicity valence. While positive and negative publicity had different effects on the sales of books by established authors, their effects were similar for books by new authors. This provides preliminary evidence for the notion that negative publicity may have positive effects because of the dissociation of valence in memory.

The pattern also casts doubt on an alternative explanation for the results. One could argue that negative reviews might have a positive effect because being reviewed is itself a signal of quality. The mere fact that a book is reviewed in the New York Times may signal that it is an outstanding book relative to the universe of books available. This explanation, however, would suggest that being reviewed (regardless of valence) should always boost sales, which the results show is not the case. Negative reviews decreased the sales of books by established authors.

\section{STUDY 2: THE ROLE OF TIME}

Study 2 has two main goals. First, it provides a more controlled examination of the effects of negative publicity. We directly manipulated both publicity valence and product awareness to examine how they influence purchase likelihood. Second, it provides a deeper examination of the role that the dissociation of valence in memory over 
time plays in these effects. Given that much of the sales data in Study 1 was in-store, and many readers get the New York Times delivered to their home, there should have been a reasonable delay between when most consumers read a review and bought books. Study 2 examines the effect of time delay more directly. Few consumers want to read bad book or see a movie they know will be terrible, but over time the valence of publicity for unknown products may be forgotten, leading positive and negative reviews to have a similar effect. To test this possibility, we manipulated whether people reported purchase likelihood either right after reading a product review, or after a delay.

For products with high awareness, we predict that review valence should influence purchase likelihood regardless of whether there is a delay. Compared to a negative review, a positive review should lead to greater purchase likelihood. In contrast, for products with low awareness, the effect of review valence on purchase likelihood should be moderated by time. Compared to a negative review, a positive review should increase purchase likelihood when participants fill out the dependent measures right away. After delay, however, this effect should dissipate.

\section{Method}

Participants $(\mathrm{N}=252)$ completed two ostensibly unrelated studies as part of a group of experiments. They were given a chance to win a $\$ 25$ gift certificate as compensation.

In the first study, we manipulated both the valence and target of a review. Regarding valence, participants were told that the researchers were interested in how people respond to linguistic devices in writing and were asked to read two book reviews 
and answer questions related to the cover story (i.e., how varied was the sentence structure?). The second review was always the same, but we manipulated whether the first review was positive or negative. In the positive review condition, participants read that book, was "a powerful, timely, and shocking story of political and legal intrigue, a story that will leave readers unable to think about our electoral process or judicial system in quite the same way ever again." It went on to suggest that the book was "overall, a delightfully entertaining read by an author who knows his subject matter." In the negative review condition, participants read that the book provided as "vivid an account as the fictional fare sold at airport kiosks — but it is also, alas, just as oversimplified, and it distorts the justice system in the same way." It went on to suggest that "sometimes there is so much going on that the novel threatens to spin out of control. In addition, despite the strength of the novel's themes, their potential effect is sometimes thwarted by cloying prose." A pretest confirmed the valence of the reviews. Participants $(\mathrm{N}=37)$ rated the valence of one of the reviews $(-3=$ extremely negative, $3=$ extremely positive $)$. Results indicated that the positive review was perceived positively $(\mathrm{M}=1.11$, compared to zero, $t(17)=3.16, p=.006)$ and the negative review perceived negatively $(\mathrm{M}=-.68$, compared to zero, $t(18)=2.82, p=.01)$.

We varied product awareness by manipulating the target of the review. In the high awareness condition, we selected a eagerly anticipated book (The Appeal) by a wellknown author (John Grisham). It was the author's first legal thriller in a number of years, and was about to be released, so there was a good deal of buzz about the book on the web. Indeed, on the strength of pre-orders alone it had risen into the top 1,000 bestselling books on Amazon.com. In the low awareness condition, we created a fictitious book. It 
was given a similar sounding name (The Report) but given that we generated it ourselves, it should be unknown. A pre-test confirmed the difference in product awareness. Of eight books rated (see Study 3 for information on the pretest method) participants were most aware of Grisham's book (relative to others in the set, $t(165)=7.95, p<.001$ ) and least aware of our fictitious book The Report (relative to others in the set, $t(165)=3.76, p$ $<.001){ }^{7}$ Thus participants in each publicity valence condition read the same review, but the product in the review varied by condition.

Finally, we manipulated when participants reported purchase likelihood. In the context of an ostensibly unrelated task, participants were given a list of four books, including the target book, and asked to rate how likely they would be to purchase each book $(1=$ not at all likely, $7=$ extremely likely $)$. Half the participants completed the purchase likelihood measures right away, while the other half first completed a long series of filler tasks (adapted from Sela and Shiv, 2009).

\section{Results}

We examined purchase likelihood in a 2 (Review Valence: Positive vs. Negative) x 2 (Time: Delay vs. No Delay) x 2 Product Awareness (Well Known vs. Unknown) ANOVA. Analysis revealed main effects of both Review Valence $\left(\mathrm{M}_{\text {Positive }}=3.33\right.$ vs. $\left.\mathrm{M}_{\text {Negative }}=2.26 ; \mathrm{F}(1,244)=19.07, \mathrm{p}<.001\right)$ and Product Awareness $\left(\mathrm{M}_{\text {Well-Known }}=3.30\right.$ vs. $\left.\mathrm{M}_{\text {Unknown }}=2.28 ; \mathrm{F}(1,244)=17.35, \mathrm{p}<.001\right)$.

\footnotetext{
${ }^{7}$ One could argue that the author is well known but the product itself is not. However, especially in the case of well-known authors, the author's name almost always accompanies publicity about the book. Further many people refer to books by well known authors by the author (e.g., "John Grisham's new thriller") rather than just the title alone.
} 
More importantly, these effects were qualified by the predicted 3-way Review Valence $\mathrm{x}$ Time $\mathrm{x}$ Product Awareness interaction $(F(1,244)=4.11, p=.04)$, Figure 1 . Focusing on known versus unknown products separately helps clarify the pattern of results. For well known products, there was only a main effect of review valence $(\mathrm{F}(1$, $94)=11.17, p<.001)$. Participants reported they would be more likely to purchase well known products that were positively (rather than negatively) reviewed, regardless of whether they reported purchase likelihood right away, or after a delay. In contrast, for unknown products, delay moderated the effect of review valence on purchase likelihood $(\mathrm{F}(1,150)=4.30, \mathrm{p}=.04)$. Review valence had an effect when participants reported purchase likelihood right away $(\mathrm{F}(1,244)=6.83, \mathrm{p}<.01)$ but this effect dissipated after delay $(F<.50 \mathrm{p}>.80)$. Viewed another way, the effect of a negative review for an unknown product became more positive after delay $(F(1,244)=5.96, p=.01)$ such that purchase likelihood after delay was similar after a positive or negative review.

Looked at another way, product awareness did not moderate the effect of review valence on purchase likelihood when participants completed the dependent measures right away $(\mathrm{F}<.10, \mathrm{p}>.85)$. After delay, however, there was a significant Product Awareness x Review Valence interaction $(F(1,121)=7.49, \mathrm{p}<.01)$, such that review valence influenced the purchase likelihood of well known products $(F(1,121)=12.08, p$ $<.001)$ but not unknown products $(\mathrm{F}<.05, \mathrm{p}>.80)$.

\section{Discussion}

Study 2 further illustrates when negative publicity will have positive effects, while also underscoring the important role of time in this process. Regardless of whether 
participants reported purchase likelihood right away or after delay, negative publicity hurt purchase of well-known products. For unknown products, however, the effect of publicity valence dissipated over time. Consistent with the notion that publicity valence for unknown products fades in memory, there was no effect of publicity valence on purchase likelihood of unknown products after a delay. In addition, for unknown products the effect of a negative review became more positive over time. This suggests that while publicity valence fades over time, increased awareness may remain, which can boost purchase likelihood.

\section{STUDY 3: INCREASING PRODUCT AWARENESS}

The first two studies support our hypotheses, but they only tell part of the story. We have argued that while publicity valence fades over time for unknown products, increased awareness may remain, which can boost purchase likelihood even when the publicity was negative. Study 3 directly tests this possibility by examining whether positive effects of negative publicity are driven by increased awareness. In addition, we measure product evaluations even when the product is not reviewed. This baseline allows us to examine how positive and negative publicity shift evaluation relative to not being reviewed at all.

We again manipulated both the valence and target of a book review, but all participants reported purchase likelihood after a long delay, and they did so for both reviewed and non-reviewed books. Thus we used a 2 (Prior Product Awareness) x 2 (Review Valence) x 2 (Product Reviewed) full factorial mixed design. This allows us to control for the mere act of reading a positive or negative review (which may affect 
evaluations through mood). We predict that while positive publicity should increase purchase likelihoods for both books, existing product awareness should moderate the effect of a negative review. Consistent with Studies 1 and 2, negative publicity should hurt purchase likelihood of the well known product but boost purchase likelihood when the product is unknown.

We also measured a number of other factors to further examine the mechanism behind these effects. Both before and after reading the review, participants rated product awareness for the two target books. We also measured product evaluations after the review. If the publicity valence fades more for unknown products, as we have suggested, then publicity valence should affect evaluations when the product is well known, but not unknown. Publicity should only increase product awareness, however, when the product is relatively unknown. Further, while product attitudes should influence the purchase likelihood of both books, change in awareness should have a stronger effect on the previously unknown book. For this previously unknown product, increased awareness should drive the effect of being reviewed on purchase likelihood.

\section{Method}

Participants $(\mathrm{N}=137$, mean age $=35)$ completed a group of studies online. They were told they would participate in a variety of studies from different experimenters and were compensated with a chance to win a $\$ 25$ gift certificate.

First, participants were asked to rate their awareness of eight books (the two target books from Study 2 plus six fillers, e.g. The Omnivore's Dilemma). Importantly, they provided their ratings by clicking on a line anchored by "Not at all Aware" and 
"Extremely Aware." No numbers appeared anywhere along the line, but based on where the participants clicked, a value between 0 and 700 was recorded. Prior to rating the books, participants were given some instructions on this rating system, as well as some practice ratings. This set-up was used to make it difficult for participants to just restate their pre-review awareness rating on the post-review awareness scales.

After filler tasks, participants completed a supposedly unrelated study in which they read a review of one of the target books. The task was similar to the one used in Study 2, and the review valence and product awareness manipulations were the same.

After more filler tasks, including the delay task from Study 2, participants completed the dependent measures. First, they used a 7-point scale to rate how likely they would be to buy each of eight books, including the two target books. On a separate page, they then completed the same awareness task they had done previously. They clicked somewhere on a non-numbered line to indicate their current product awareness. Next, they used a 7-point scale to their product evaluation of the same eight books. Finally, they completed demographic measures and were thanked for their time.

\section{Results}

Preliminary Analyses. We subtracted pre-review awareness from post-review awareness to create an awareness change score for the two target products. We controlled for purchase likelihood variation across participants by averaging purchase likelihoods for non-target books, and used this measure as a covariate in subsequent analyses. We examined awareness change, product attitudes, and purchase likelihood for each of the target books using a 2 Prior Product Awareness (Unknown vs. Well-Known), 
x 2 Review Valence (Positive vs. Negative) x 2 Product Reviewed (Reviewed vs. Other Book Reviewed) Repeated Measures ANOVA. Again, since all participants rated purchase likelihood for both books, even though they only read a review for one of them, we can compare how prior product awareness and review valence affect purchase likelihood relative to a control situation where the product was not reviewed.

Change in Awareness. First, we examined how publicity influences product awareness. As predicted, being reviewed affected unknown and well-known products differently, as indicated by a Product Reviewed x Prior Product Awareness interaction $(F(1,134)=4.89, p=.03)$. Compared to not being reviewed, publicity increased awareness of the unknown product $(\mathrm{M}=48.21$ vs. $9.29 ; F(1,134)=5.909, p=.02)$. In contrast, being reviewed had no effect on awareness of the well-known product $(F(1$, $134)<1, p>.35)$. No other effects reached significance $(F s<2.6)$. In sum, publicity only increased awareness when the product was not well-known already.

Product Evaluations. Second, we examined how publicity influences evaluations. As predicted, review valence affected unknown and well-known products differently, as indicated by the Product Awareness x Product Reviewed x Review Valence interaction $(F(1,134)=3.47, p=.06)$. Focusing on each book type separately helps clarify the pattern of results. For the well-known product there was a significant Product Reviewed $\mathrm{x}$ Review Valence interaction $(F(1,134)=4.16, p=.04)$. Compared to cases where the book was not reviewed, a positive review slightly increased evaluations ( $M=4.82$ vs. $4.67 ; F(1,134)<.35, p>.50)$, while a negative review decreased evaluations $(M=4.00$ vs. $4.86 ; F(1,134)=4.14, p=.04)$. In contrast, attitudes towards the unknown book did 
not significantly differ across conditions $(F \mathrm{~s}<.6)$, consistent with the notion that publicity valence fades over time for unknown products.

Purchase Likelihood. Next, we examined how publicity influences purchase likelihood. Not surprisingly, people said they would be more likely to purchase John Grisham's new thriller $(\mathrm{M}=3.20)$ than an unknown book $(\mathrm{M}=2.20 ; F(1,134)=6.79, p$ $=.01)$ More importantly, as predicted, review valence affected unknown and well-known products differently, as indicated by the Product Awareness x Product Reviewed x Review Valence interaction $(F(1,134)=4.10, p<.05)$, Figure 2. Relative to not being reviewed, negative publicity decreased purchase likelihood of the well-known book ( $F(1$, $134)=6.44, p=.01)$ but increased purchase likelihood of the unknown book $(F(1,134)$ $=3.47, p=.06$ ). Positive reviews, on the other hand, had similar effect on both types of books. Relative to not being reviewed, positive publicity increased purchase likelihood of both the well-known (though not significantly so, $F(1,134)=.37, p=.54$ ) and unknown book $(F(1,134)=4.20, p=.04)$.

Looked at another way, for the well-known book, Review Valence influenced purchase likelihood $(F(1,134)=5.35, p=.02)$, such that a positive publicity helped more than a negative publicity. For the unknown book, however, both positive and negative publicity had a similar effect in increasing purchase likelihood $(F(1,134)<.3, p>.60)$.

Link between Product Evaluations, Awareness, and Purchase Likelihood. We also examined how purchase likelihood varied based on product evaluation and change in awareness. A multiple regression examined how purchase likelihood for the reviewed book varied based on product type (whether the product was well-known or unknown), product evaluations, change in product awareness, and interactive effects of book type 
with product evaluations and awareness change. Results revealed interactive effects of book type with both product evaluations $(\beta=.18, t(132)=3.38, p=.001)$ and awareness change $(\beta=-.12, t(132)=2.34, p=.02)$.

To clarify the pattern of results we ran separate regressions for well known and unknown products, where product evaluation and change in awareness predicted purchase likelihood. For the well-known product, evaluations were linked to purchase likelihood $(\beta=.57, t(132)=8.61, p<.001)$ but change in awareness was not $(\beta=.06$, $t(132)=1.01, p>.30)$. For the previously unknown product, however, both evaluations $(\beta=.20, t(132)=2.33, p=.02)$ and change in awareness $(\beta=.32, t(132)=3.55, p<$ .001) were linked to purchase likelihood. These results indicate that while purchase likelihood for the well-known product was driven by product attitudes, for the unknown product, increased awareness played a more important role.

A mediational analysis (Baron and Kenny 1986) further demonstrates that increased purchase likelihood for the previously unknown product was driven by increased awareness. Being reviewed was linked to increased purchase likelihood ( $\beta=$ $.16, t(136)=2.78, p<.01)$ and change in awareness $(\beta=.23, t(136)=2.70, p<.01)$, but when both review and awareness were included in the regression, change in awareness remained significant $(\beta=.29, t(135)=5.23, p<.001)$ while being reviewed reduced to marginality $(\beta=.10, t(135)=1.78, p=.08)$. A Sobel test confirmed the pattern of mediation $(\mathrm{z}=2.40, p<.02)$.

\section{Discussion}


Results of Study 3 again demonstrate conditions under which negative publicity will have positive, versus negative, effects. Whether the same negative review increased or decreased purchase likelihood, relative to no publicity, depended on existing awareness about the cultural product being reviewed. While a negative review decreased purchase likelihood of a book that was already well-known, it increased purchase likelihood for a previously unknown book.

The findings also demonstrate the important role of increased product awareness in positive effects of negative publicity. For a product that was already well-known, publicity valence determined the outcome. Publicity did not boost awareness, but the valence of the review influenced product evaluations and led people to be more likely to purchase after a positive, rather than negative review. The process differed, however, for an unknown product. Regardless of whether the publicity was positive or negative, it increased product awareness, which, in turn, increased purchase likelihood. This is consistent with the notion that negative publicity increases sales through affecting the consideration set.

In addition, the findings cast doubt on a number of alternative explanations. While one could argue that negative publicity might increase purchase likelihood through making the product more familiar, and thus boosting liking, the evaluation results suggest this in unlikely. Though being negatively reviewed boosted product awareness for the book by the unknown author, it did not increase product evaluations. In addition, the fact that review valence influenced evaluations of well known products, but not unknown products, provides further evidence that publicity valence fades over time for products 
that are less well known. The mediation by awareness also casts doubt on an alternative account based on involvement.

\section{GENERAL DISCUSSION}

While conventional wisdom suggests that any publicity is good publicity, existing research has documented only downsides of negative reviews and information, such as decreased product evaluations and reduced sales. This article helps unify these perspectives. Building on research regarding product awareness and evaluation, we theorized one type of situation when negative publicity might boost purchase. Our investigation is the first to show beneficial effects of negative publicity, and further to delineate conditions under which negative publicity will have positive versus negative effects.

Using a combination of experimental methods and econometric analysis, we demonstrate that the effect of negative publicity depends on existing product awareness. While negative publicity hurt products that already had broad awareness (Studies 1-3), it helped products that were relatively unknown. These effects were shown for both purchase likelihood (Studies 2-3), as well as actual sales (Study 1). The studies further demonstrate the importance of a delay between publicity and purchase opportunity in these effects (Study 2), as well as the mediating role of product awareness (Study 3). Review valence fades over time for unknown products and negative reviews increase purchase likelihood by making people more aware of the product. Finally, by combining controlled experiments (Studies 2 and 3) and empirical analysis of actual product sales 
(Study 1), we examine the underlying mechanism behind positive effects of negative publicity while also demonstrating their importance for actual product performance.

\section{Implications and Future Research}

Our theorizing also helps unify these findings with prior results showing that negative publicity decreases sales (e.g., Basuroy et al. 2003). For the most part, prior work has focused on relatively popular cultural products (i.e., major films) which should already have at least some awareness among the population. While around 700 feature films are released in the U.S. every year, the number of new books numbers in the hundreds of thousands (Bogart 2001; Motion Picture Association 2006). Consequently, existing product awareness should be higher for reviewed movies than reviewed books, and negative effects of negative publicity should be more likely.

Even when general awareness is low, however, we suggest that negative publicity will be unlikely to have a positive effect when product awareness and accessibility are high among the people reached. Chevalier and Mayzlin (2006), for example, examine consumer reviews on internet booksellers and find that negative reviews hurt sales. Though general awareness of most books should be low, the observed effects may have been similar to those found in work on movie reviews because product awareness is necessarily high among people reached by the reviews. Reviews on sites like Amazon.com appear on the same page as the book itself, and to the degree that consumers have searched for the book by name, product awareness is already reasonably high. Consequently, the review should have little ability to increase accessibility or awareness and will be unlikely to boost sales. However, in situations where people are 
browsing the New York Times book review section, or glancing to see what movies happen to be reviewed that week, the review may be the first time they hear about the product and thus negative publicity may still have positive effects.

More generally, our theorizing helps explain how publicity in general, regardless of valence, will impact product success under different circumstances. Publicity should be more likely to have a positive impact on sales in situations where existing product awareness or accessibility is low. Consistent with this suggestion, Reinstein and Snyder (2005) report that reviews only influenced demand for more obscure films (e.g., those that were narrowly released). When we estimate separate coefficients for the three author categories in our own book sales data, the coefficient is largest for the new authors (though the relative imprecision of the estimates prevents us from drawing any strong conclusions). Overall, publicity should have less of an impact on widely released books or movies because everyone knows about them already.

Our studies focused on product reviews, but similar effects may also hold for other types of publicity such as word of mouth. Researchers have long been interested in how word-of-mouth influences diffusion and sales (Arndt 1967; Coleman, Katz, and Menzel 1966; Godes and Mayzlin 2009; Iyengar, Van den Bulte and Valente 2008). This research area, however, generally assumes that negative word-of-mouth should hurt product success (e.g., Goldenberg, Libai, Moldovan, and Muller 2007, also see numerous popular press books on the importance of decreasing negative WOM, Blackshaw 2008). While this assumption seems fair, the studies reported here indicate that it may not always hold. Just as negative reviews can increase the accessibility of unknown products, negative word-of-mouth may have similar effects. Hearing that a friend hated a 
restaurant should definitely decrease product evaluations, but it should also increase product awareness and accessibility which may have positive downstream effects on sales.

Future research might examine other factors that shape how publicity and product reviews influence consumer choice. One such factor is the extremity of the review. While Study 2 illustrated that the effects of negative publicity become more positive after delay, its immediate effects may depend on whether it is weakly or strongly negative. While really negative publicity should turn most people away, slightly negative publicity may increase interest enough to have positive effects even in the short term. Another factor is whether the review provides reasons that are relevant to the reader. Just as added product features can sometimes have perverse effects and hurt brand choice among consumers who see them as irrelevant to their own interests (Simonson, Carmon, and O'Curry 1994), reviews that contain irrelevant reasons might also have perverse effects and actually lead to more positive evaluations. Future work might also examine when negative publicity boosts product evaluations. Repeated exposure to a stimulus can increase liking (Zajonc, 1968), and thus even negative attention might increase choice and sales through making products more familiar.

Another interesting question is whether prior evaluations influence exposure to reviews in the first place. People who have strong positive attitudes towards a product may be less likely to even consider reading a negative review. One could also argue that negative reviews may be more interesting to read and more likely to be shared with friends, and if so, this could lead one negative review to generate greater word-of-mouth and have a larger overall effect than a similar positive review. Gaining deeper insight 
into the effects of publicity on sales requires understanding not only how publicity influences information processing and attitudes, but also word of mouth, exposure likelihood, and memory.

It would also be interesting to examine whether, through making the product more accessible, negative attention to concepts that are conceptually linked to a product can also influence sales (see Berger and Fitzsimons 2008). Actors, musicians, and even writers sometimes receive negative news coverage for various indiscretions. Could negative press about a musician affect the success of their albums, even if the publicity never mentions their music?

Other data we collected suggests that it may. We were able to obtain Amazon.com sales rankings for a number of Michael Jackson albums over time as well as a measure of negative attention to the star (i.e., the number of Top 50 newspaper articles over time that mentioned his various run ins with the law). Analyses indicated that negative publicity, even of an indirect nature, was linked to sales. Jackson sold more albums in times when he was in the news for child molestation charges or dangling his baby over a balcony. Though these events have nothing to do with the quality of Jackson's music, they may influence sales through a similar mechanism as product reviews. Just as product reviews should increase the likelihood a product is top-of-mind, so too should attention to conceptually related cues in the environment (Berger and Fitzsimons 2008). Increased media attention to Jackson should make him more accessible in consumers' minds, which, in turn, should increase the likelihood that they buy his music. Similarly, negative attention to CEOs or other public figures (e.g., Paris Hilton) may affect the sales of related products because they increase product 
accessibility. Consequently, the success of products, ideas, and behaviors may vary over time with the prevalence of related cues in the environment (Berger and Heath 2005). The current findings on this issue are far from conclusive, but they suggest that further research should examine not only direct negative publicity (i.e., product reviews), but also publicity that is of a more indirect nature.

In summary, though companies and individuals often try to squash negative publicity, our findings indicate that in some cases it can actually have positive effects. Though producers of major motion pictures or highly anticipated books might want to attempt to deaden negative press, smaller producers might want to allow, or even fan the flames of negative publicity. This does not mean that all negative information will have positive effects, and it is still important to understand consumer sentiment (see Goldenberg, Feldman, Fresco, Netzer, and Ungar 2009). That said, not all negative publicity or word of mouth should be quashed. Consumers often attempt to discount direct advertising, but because negative publicity does not seem like a direct product appeals, it may slip in under the radar and thus have a more pronounced effect. In summary, though negative publicity is not always a good thing, in some cases, negative can actually be positive. 
TABLE 1:

SUMMARY STATISTICS FOR REVIEWS (STUDY 1)

\begin{tabular}{|c|c|c|c|c|c|}
\hline & \multirow[b]{2}{*}{ Mean } & \multirow[b]{2}{*}{$\begin{array}{l}\text { Std. } \\
\text { Dev. }\end{array}$} & \multicolumn{3}{|c|}{ Percentiles } \\
\hline & & & .10 & .50 & .90 \\
\hline \multicolumn{6}{|l|}{ Books: } \\
\hline List Price & $\$ 24.63$ & $\$ 3.12$ & $\$ 23.00$ & $\$ 24.95$ & $\$ 25.95$ \\
\hline Average weekly sales & $2,685.5$ & $10,831.9$ & 48.9 & 368.3 & $3,570.2$ \\
\hline Week reviewed & 7.7 & 8.2 & 3 & 5 & 12 \\
\hline \multicolumn{6}{|l|}{ Reviews: } \\
\hline Number of sentences & 45.5 & 22.6 & 12 & 48 & 74 \\
\hline Number opinionated & 6.8 & 4.4 & 2 & 6 & 13 \\
\hline Percent opinionated & $16.0 \%$ & $8.9 \%$ & $7.1 \%$ & $14.6 \%$ & $25.0 \%$ \\
\hline Percent positive & $55.3 \%$ & $30.3 \%$ & $11.1 \%$ & $52.6 \%$ & $100.0 \%$ \\
\hline
\end{tabular}


TABLE 2:

THE IMPACT OF REVIEWS ON SALES FOR AUTHORS WITH VARYING AMOUNTS OF PRIOR AWARENESS (STUDY 1)

\begin{tabular}{rll} 
& Estimates & S.E. \\
\hline \hline Positive Review & & \\
x (<2 previous titles) & $.347^{* * *}$ & .103 \\
x (2-9 previous titles) & $.277^{* * *}$ & .095 \\
x ( $>10$ previous titles) & $.417^{* *}$ & .179 \\
Negative Review & & \\
x (<2 previous titles) & $.372^{*}$ & .202 \\
x (2-9 previous titles) & .137 & .162 \\
x ( $>10$ previous titles) & $-.145^{\wedge}$ & .098 \\
& & \\
Weeks since release & $-.051^{* * *}$ & .012 \\
$R^{2}$ & \multicolumn{2}{c}{.182} \\
\hline \hline
\end{tabular}

Each specification also includes a full set of week fixed effects, a variable for weeks since review, and four indicators for whether the book was announced as a television book club pick. There are 1942 observations. The estimate for negative reviews on books by authors with more than 10 prior titles is slightly imprecise due to the relatively small sample size of only 23 books. ${ }^{\wedge} p<.15, * p<.10, * * p<.05$, $* * * \mathrm{p}<.01$ 
FIGURE 1:

EFFECT OF REVIEW VALENCE, PRODUCT AWARENESS, AND TIME DELAY ON PURCHASE LIKELIHOOD (STUDY 2)
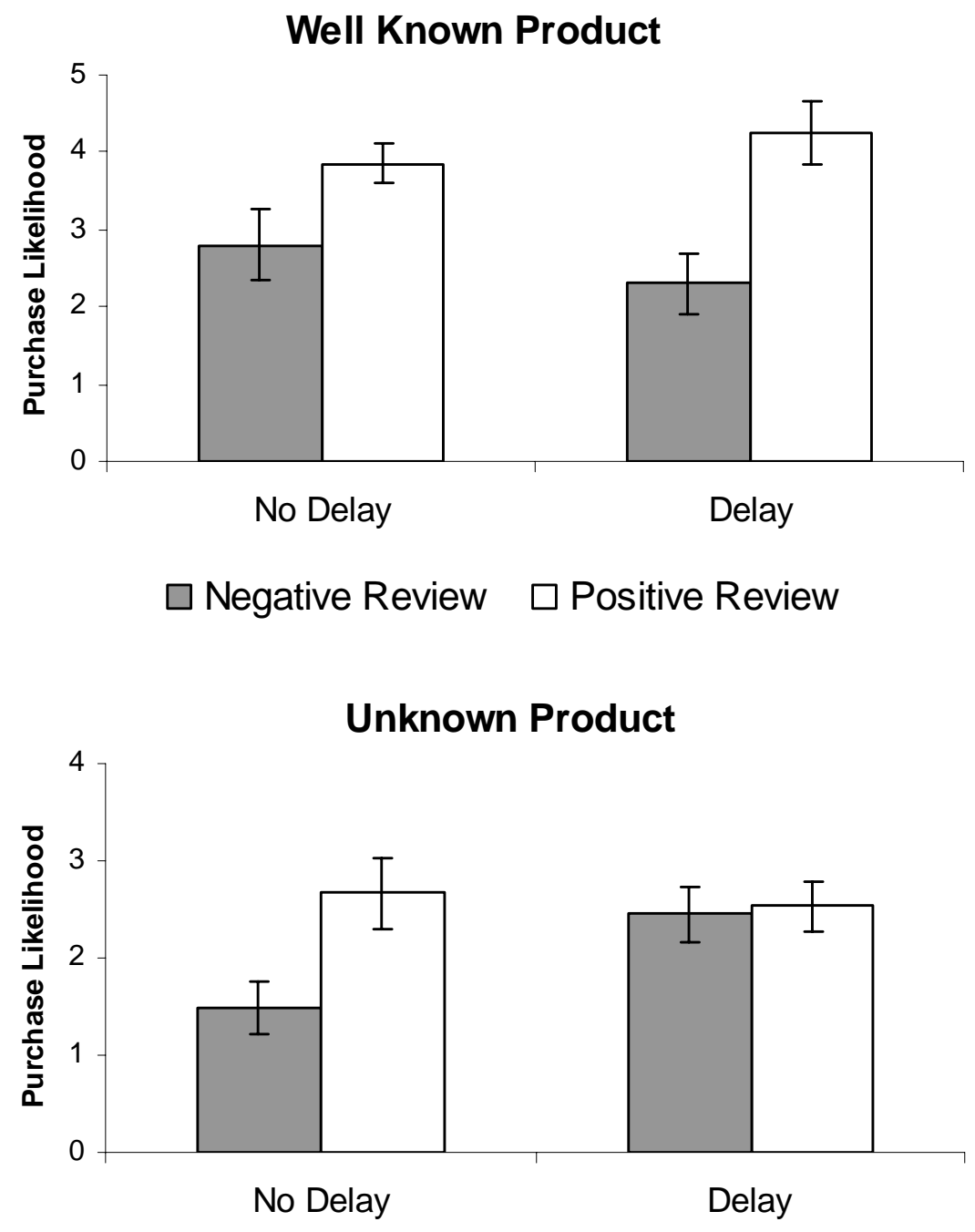
FIGURE 2:

EFFECT OF REVIEW VALENCE AND EXISTING PRODUCT AWARENESS ON PURCHASE LIKELIHOOD (STUDY 3)

\section{Well Known Product}

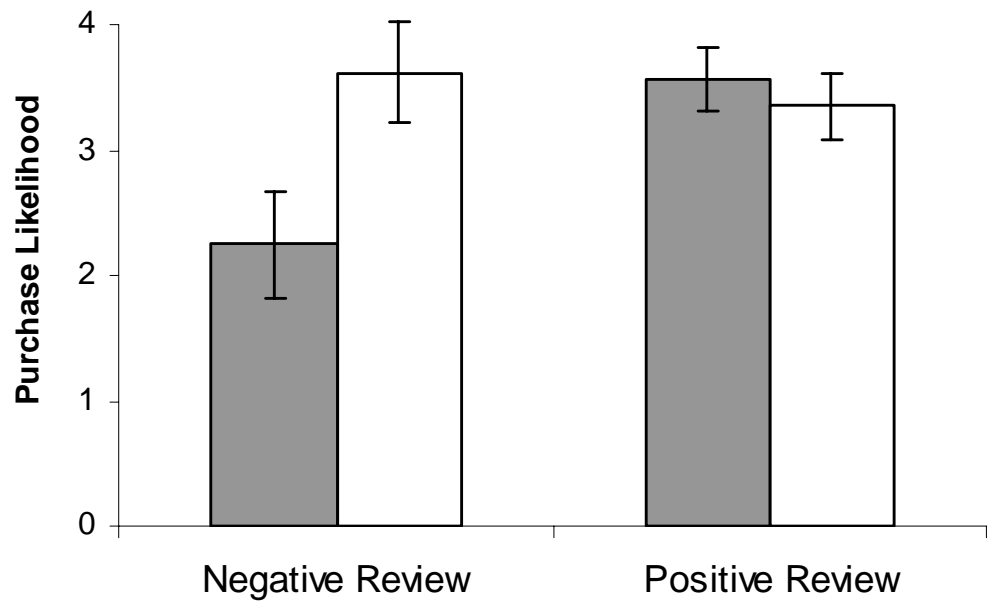

$\square$ Reviewed $\square$ Not Reviewed (other book reviewed)

\section{Unknown Product}

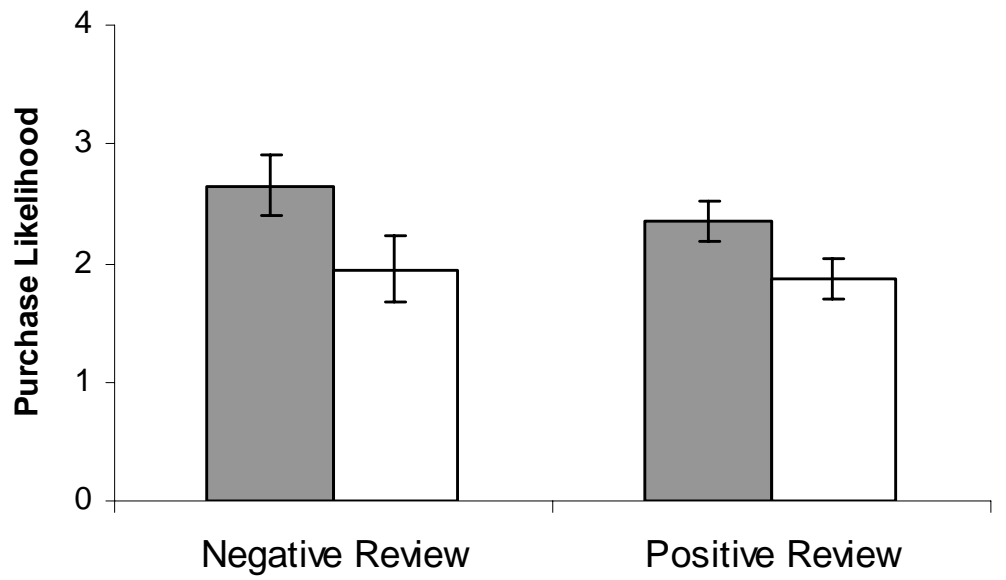




\section{REFERENCES}

Ahluwalia, Rohini, Robert E. Burnkrant, and H. Rao Unnava (2000), "Consumer Response to Negative Publicity: The Moderating Role of Commitment," Journal of Marketing Research, 37 (May), 203-214.

Alba, Joseph W. and J. Wesley Hutchinson (1987), "Dimensions of Consumer Expertise," Journal of Consumer Research, 13 (March), 411-454.

Anderson, John R. (1995). Learning and Memory: An Integrated Approach, New York: John Wiley and Sons, Inc.

Arndt, Johan (1967), "Role of Product-Related Conversations in the Diffusion of a New Product," Journal of Marketing Research, 4, 291-5.

Baron, Reuben M. and David A. Kenny (1986), "The Moderator-Mediator Variable Distinction in Social Psychological Research: Conceptual, Strategic, and Statistical Considerations," Journal of Personality and Social Psychology, 51 (Dec), 1173-82.

Basuroy, Suman, Subimal Chatterjee, and S. Abraham Ravid (2003), "How Critical Are Critical Reviews? The Box Office Effects of Film Critics, Star Power, and Budgets," Journal of Marketing, 67 (4), 103-17.

Berger, Jonah and Chip Heath (2005), "Idea Habitats: How the Prevalence of Environmental Cues Influences the Success of Ideas," Cognitive Science, 29 (2), 195-221.

Berger, Jonah and Gráinne M. Fitzsimons (2008), "Dogs on the Street, Pumas on Your Feet: How Cues in the Environment Influence Product Evaluation and Choice," Journal of Marketing Research, 45(1), 1-14.

Blackshaw, Pete (2008), Satisfied Customers Tell Three Friends, Angry Customers Tell 3,000: Running a Business in Today's Consumer-Driven World, Broadway Business.

Bogart, Dave (2001), The Bowker Annual Library and Book Trade Almanac, New York: R. R. Bowker.

Burrough, Bryan (2006), "Sleeping with the Fishes," Vanity Fair, December 1, 244-256.

Chevalier, Judith and Dina Mayzlin (2006), "The Effect of Word of Mouth Online: Online Book Reviews," Journal of Marketing Research.

Clemons, Eric K., Guodong Gao and Lorin M. Hitt (2006), "When Online Reviews Meet Hyperdifferentiation: A Study of the Craft Beer Industry," Journal of Management Information Systems, 23 (2), 149-171.

Coleman, James S., Elihu Katz, and Herbert Menzel (1966), Medical Innovation: A Diffusion Study, Indianapolis: Bobbs-Merrill.

Dellarocas, Chrysanthos, Xiaoquan Zhang and Neveen F. Awad (2007), "Exploring the Value of Online Product Reviews in Forecasting Sales: The Case of Motion Pictures," Journal of Interactive Marketing, 21, 23-45.

Greene, Bob (1978), “Worms? McDonald's Isn't Laughing," The Chicago Tribune, Nov 20, A1.

Godes, David and Dina Mayzlin (2009), "Firm-Created Word-of-Mouth Communication: Evidence from a Field Test," Marketing Science, 28, 721-739.

Goldenberg, Jacob, Barak Libai, Sarit Moldovan, and Eitan Muller (2007), "The NPV of Bad News," International Journal of Research in Marketing, 24, 186-2000. 
Goldenberg, Jacob, Ronen Feldman, Moshe Fresco, Oded Netzer, and Lyle Ungar (2009), "Using Text Using Text Mining to Analyze User Forums," Journal of Online Information Review, forthcoming.

Hannah, Darlene B. and Brian Sternthal (1984), "Detecting and Explaining the Sleeper Effect," Journal of Consumer Research, 11 (September), 632-642.

Hauser, John R. (1978), "Testing the Accuracy, Usefulness and Significance of Probabilistic Models: An Information Theoretic Approach," Operations Research, 26(3), 406-421.

Hendricks, Ken and Alan Sorensen (2009), "Information and the Skewness of Music Sales," Journal of Political Economy, 117, 324-369.

Higgins, E. Tory and Gillian King (1981), "Accessibility of Social Constructs: Information-Processing Consequences of Individual and Contextual Variability," in Personality, Cognition, and Social Interactions, Nancy Cantor and John F. Kihlstrom eds, Hillsdale, NJ: Lawrence Erlbaum, 60-81.

Huang, Jen-Hung and Yi-Fen Chen (2006), "Herding in Online Product Choice," Psychology and Marketing, 23 (5), 413-428.

Iyengar, Raghuram, Christophe Van den Bulte, Thomas W. Valente, (2008), "Opinion Leadership and Social Contagion in New Product Diffusion," Marketing Science Institute Report No. 08-120, Cambridge, MA: Marketing Science Institute.

James, Caryn (2006), "When the Bad Buzz Arrives Before the Movie Does," The New York Times, September 26, A1.

Liu, Yong (2006), "Word-of-Mouth for Movies: Its Dynamics and Impact on Box Office Revenue," Journal of Marketing, 70 (3), 74-89

Lynch, John R. Jr. and Thomas K. Srull (1982), "Memory and Attentional Factors in Consumer Choice: Concepts and Research Methods," Journal of Consumer Research, 9 (June), 18-37.

Mitra, Anusree, and John G. Lynch, Jr. (1995), "Toward a Reconciliation of Market Power and Information Theories of Advertising Effects on Price Elasticity," Journal of Consumer Research, 21 (March), 644-659.

Moe, Wendy W. (2009), "How Much Does a Good Product Rating Help a Bad Product? Modeling the Dynamics of Online Product Ratings and Their Effects on Sales," Working Paper, University of Maryland .

Moore, Danny L and Hutchinson, J. Wesley (1985), "The Influence of Affective Reactions to Advertising: Direct and Indirect Mechanisms of Attitude Change," In L. F. Alwitt and A.A. Mitchell (Eds.), Psychological Processes and Advertising Effects: Theory, Research, and Application, New York: Lawrence Erlbaum.

Moore, Danny L. and J. Wesley Hutchinson (1983), "The Effects of Ad Affect on Advertising Effectiveness," R. P. Bagozzi and A. M. Tybout (eds.), Advances in Consumer Research, 10, 526-531.

Motion Picture Association of America (2006), 2006 U.S. Theatrical Market Statistics, (accessed September 1, 2006), [Available at http://www.mpaa.org/2006-USTheatrical-Market-Statistics-Report.pdf].

Nedungadi, Prakash (1990), "Recall and Consumer Consideration Sets: Influencing Choice Without Altering Brand Evaluations," Journal of Consumer Research, 17 (December), 263-76. 
New York Times Company (2006), 2006 Annual Report, (accessed May 24, 2007), [available at http://www.nytco.com/pdf-reports/2006ar10K/2006NYTannual.pdf].

O'Connell, Vanessa (2006), "Ripe for Change: Wine Sales Thrive As Old Barriers Start to Crumble," The Wall Street Journal, August 25, A1.

Petty, Richard E. and John T. Cacioppo (1979), "Issue Involvement Can Increase or Decrease Involvement by Enhancing Message-Relevant Cognitive Responses," Journal of Personality and Social Psychology, 37 (October), 1915-1926

Reinstein, David A. and Christopher M. Snyder (2005), "The Influence of Expert Reviews on Consumer Demand for Experience Goods: A Case Study of Movie Critics," Journal of Industrial Economics, 53 (1), 27-51.

Sela, Aner and Baba Shiv (2009), "Unraveling Priming: When Does the Same Prime Activate a Goal versus a Trait?” Journal of Consumer Research, forthcoming.

Simonson, Itamar, Ziv Carmon, and Sue O'Curry (1994), "Experimental Evidence on the Negative Effect of Product Features and Sales Promotions on Brand Choice," Marketing Science, 13(Winter), 23-40.

Skurnik, Ian, Carolyn Yoon, Denise C. Park and Norbert Schwarz (2005), "How Warnings about False Claims Become Recommendations," Journal of Consumer Research, 31 (4), 713-724.

Stigler, George J. (1961), “The Economics of Information,” Journal of Political Economy, 69 (June), 213-25

Tybout, Alice M., Bobby J. Calder, and Brian Sternthal (1981), "Using InformationProcessing Theory to Design Marketing Strategies," Journal of Marketing Research, 28 (February), 73-79.

Van den Bulte, Christophe and Gary L. Lilien (2001), "Two-Stage Partial Observability Models of Innovation Adoption, Working paper, The Wharton School.

Yabroff, Jennie (2006), "Coming of Age," Newsweek, December 18, 8.

Winer, Russell S. (1999), "Experimentation in the 21st Century: The Importance of External Validity," Journal of the Academy of Marketing Science, 27 (3), 349-58

Wittink, Dick R. (2004) “Journal of Marketing Research: 2 Ps," Journal of Marketing Research, 41 (February), 1-6.

Wyatt, Robert O. and David P. Badger (1984), "How reviews affect interest in and evaluation of film," Journalism Quarterly, 61, 874-878.

Wyer, Robert S. and Thomas K. Srull (1981), "Category Accessibility: Some Theoretical and Empirical Issues Concerning the Processing of Social Stimulus Information," in Social Cognition: The Ontario Symposium, Vol. 1, E. Tory Higgins, C. Peter Herman, and Mark P. Zanna, eds. Hillsdale, NJ: Erlbaum, 161-197.

Zajonc, Robert B. (1968), “Attitudinal Effects of Mere Exposure," Journal of Personality and Social Psychology: Monograph Supplement, 9 (2), 1-27. 